Fifth International Conference on Sustainable Construction Materials and

Technologies. http://www.claisse.info/Proceedings.htm

\title{
Push-out experimental evaluation of pultruded FRP-concrete composites
}

\author{
Offiong Etim*, Alfred Kofi Gand, Messaoud Saidani, Okon Eta Ekpo and Pam Fom
}

Sustainable Materials, Structures and Geotechnics Research Group, School of Energy, Construction and Environment, Coventry University, Coventry, UK

*Corresponding author: Email: etimo@uni.coventry.ac.uk (O. O. Etim)

\begin{abstract}
This paper discusses the recent investigation into the composite action of pultruded Glass Fibre Reinforced Polymer (GFRP) and concrete hybrid systems, under static push-out tests. The experimental study carried out in two phases sought to determine the characteristic load-slip behaviour of the GFRP-concrete composites, modes of failure and associated variations in shear stud sizes and arrangements under the varied push-out load capacity. Six composite test specimens were fabricated using GFRP flange sections, mechanically connected to normal density concrete slabs with shear studs. Phase I test investigations considered the variations in the stud arrangement using $19 \mathrm{~mm}$ diameter stud sizes. Phase II experimental programs accessed the effect of stud size variations using stud sizes $12 \mathrm{~mm}$ and $16 \mathrm{~mm}$. The dominant failure mode observed was the bearing failure on GFRP flanges. Stud sizes of $19 \mathrm{~mm}$ and above will result in extreme fibre failures across the clearance holes therefore, it may be safe to adopt the $16 \mathrm{~mm}$ stud size as a higher stud boundary for GFRP-concrete composites.
\end{abstract}

Keywords: FRP-concrete composites, FRP-concrete hybrid system, shear connectors, Push-out tests, and Bolted connections

\section{INTRODUCTION AND BACKGROUND REVIEW}

Over the years, the construction industry has taken advantage of the enormous global strides made in technology to witness a creative and innovative advancement of construction materials and material properties. Without a doubt, there has been a progressive widespread of composite construction given to the fact that it provides improvement to the mechanical properties of structural members. The use of composite action between steel and concrete achieved through shear connectors is a well-established cost-effective arrangement for floor systems in multi-story steel frame building structures as well as in bridge deck construction (Dai, Lam \& Saveri, 2015). 
For a long time, steel-concrete composite (SCC) construction has been one of the fastest moving, economical and eco-friendly methods of construction and has been extensively used in high rise buildings as well as in medium span bridge decks (Prakash A, 2012). Nonetheless, steel has its disadvantages, which include its heavy weight and highly corrosive nature demanding frequent maintenance during its use in the long term. To this end, the development of a new material called Fibre reinforced polymer (FRP) over seven decades ago, originally limited to the military and aerospace industry, has opened the door for its application in the construction industry. The last two decades have seen the use of fibre reinforced polymer materials to provide a favourable solution to structures deteriorating from the corrosion and fatigue of steel elements. Hybrid beams made of pultruded fibre-reinforced polymer (PFRP) connected to reinforced concrete (RC) slabs are regarded as novel cost-effective and structurally- efficient elements (Neagoe and Gil, 2015).

In composite beam design, headed stud shear connectors and shear bolts are commonly used to transfer longitudinal shear across the interface of the composite materials. They are the most common type of shear connectors used in composite beams and bridges. Push-out tests are usually used to investigate the behaviour and suitability of shear connections (Nguyen and Kim, 2009). Besides experimental study and push-out tests, extensive parametric study has also been carried out on stud shear connectors of varied sizes as well as concretes of different compressive strength.

\section{CONFIGURATION, SETUP AND INSTRUMENTATION}

The generic component build-up for each composite connection was the same for all specimens. The composite connection under investigation remains pultruded glass fibre reinforced polymer (GFRP) I-beam section and concrete. However, steel reinforcement and shear studs are vital components with significant roles in establishing satisfactory composite performance. The GFRP profile of height $600 \mathrm{~mm}$ was of a uniform constant cross-sectional geometry $(200 \mathrm{~mm} \times 200 \mathrm{~mm}$ and average thickness of $10 \mathrm{~mm}$ ) connected on both flanges to two precast concrete slabs of constant cross-sectional geometry $(500 \mathrm{~mm} \times 550 \mathrm{~mm} \times 150 \mathrm{~mm}$ in width, length and thickness) respectively. The demountable shear studs adopted to ensure composite action between the two distinct materials characterised of an 8.8 grade of steel bolts with $12 \mathrm{~mm}, 16 \mathrm{~mm}$ and $19 \mathrm{~mm}$ diameter sizes respectively. $10 \mathrm{~mm}$ mild steel reinforcements were used for confinement strengthening and stability of the normal density concrete (see Figure 2). 


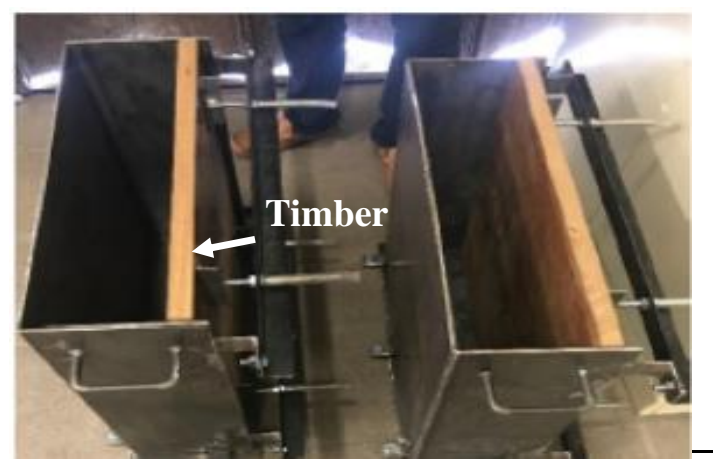

Figure 1. Bespoke concrete casting Mould

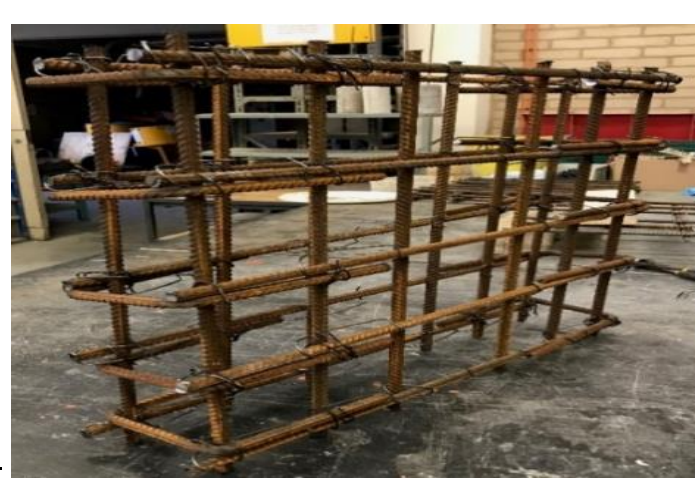

Figure 2. Concrete confinement setup

All concrete mixes were cured in a prefabricated mould comprising of a steel metal sheet (6mm thickness) welded together with an adjustable wooden closure to establish control for slab thickness as seen in Figure 1.

\subsection{Phase I Test Specimens}

The composite connection was achieved using a constant stud size of $19 \mathrm{~mm}$ diameter. Three stud configurations was developed and reflected in the labelling of the specimen. The stud arrangement on the three specimens included 2no. bolts per row for a singlerow, 2no. bolts per row for a double-row and a staggered bolt configuration of 6 no. bolts, respectively (See Figure 3). The two stud single-row configuration was modelled after the provisions of BS 5400-5 (2005) and the two stud double-row as provided in Eurocode 4 (BS EN 1994-1: 2004). The staggered 6no. bolt configuration was modelled after common practice in construction. The specimens were labelled to reflect the configuration as follows; PO-SR-S1, PO-DR-S2 and PO-SG-S3.PO represented Pushout; SR, DR, SG represented single-row, double-row and staggered configurations, respectively; and S1 represented test specimen 1, 2 or 3.

\subsection{Phase II Test Specimens}

The specimens under this phase were of a constant configuration with varying stud sizes; two specimens adopted $12 \mathrm{~mm}$ stud size diameter and the third specimen used $16 \mathrm{~mm}$ stud size diameter respectively. Specimen designation of codes carefully reflected the size of the stud. PO-12B-S4 can be illustrated as; PO represent push-out, 12B represents $12 \mathrm{~mm}$ diameter stud $\mathrm{S} 4$ represents specimen number 4 . However, one specimen was characterised with the use of $16 \mathrm{~mm}$ diameter studs while the other two specimens used $12 \mathrm{~mm}$ diameter studs respectively 


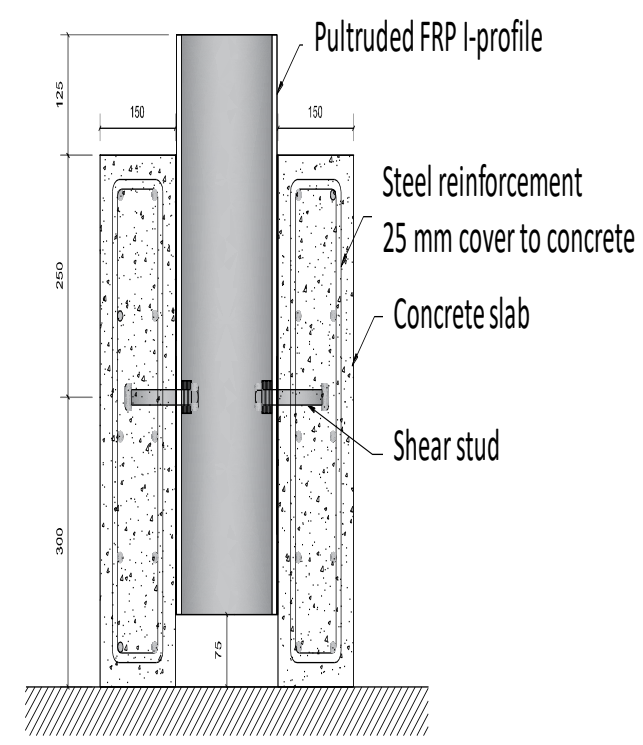

(a) Single row bolt (PO-SR-S1)

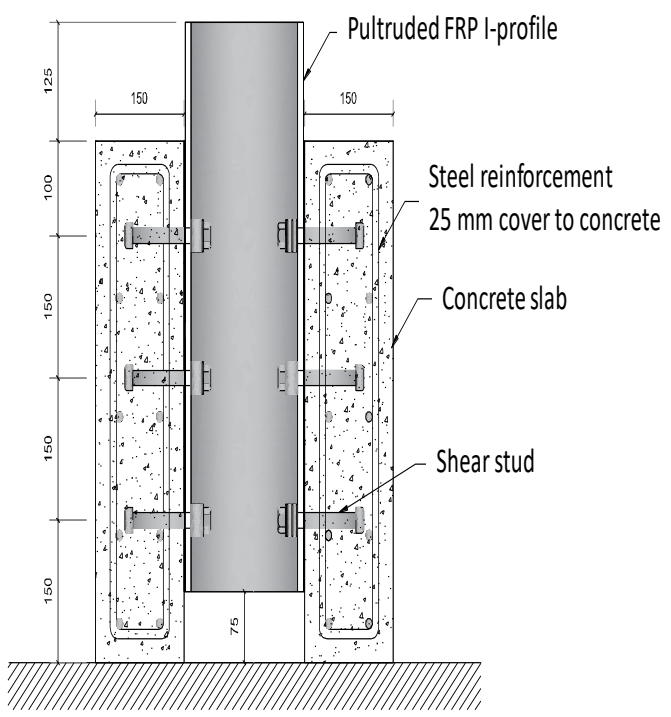

(b) Staggered bolt (PO-SG-S2)

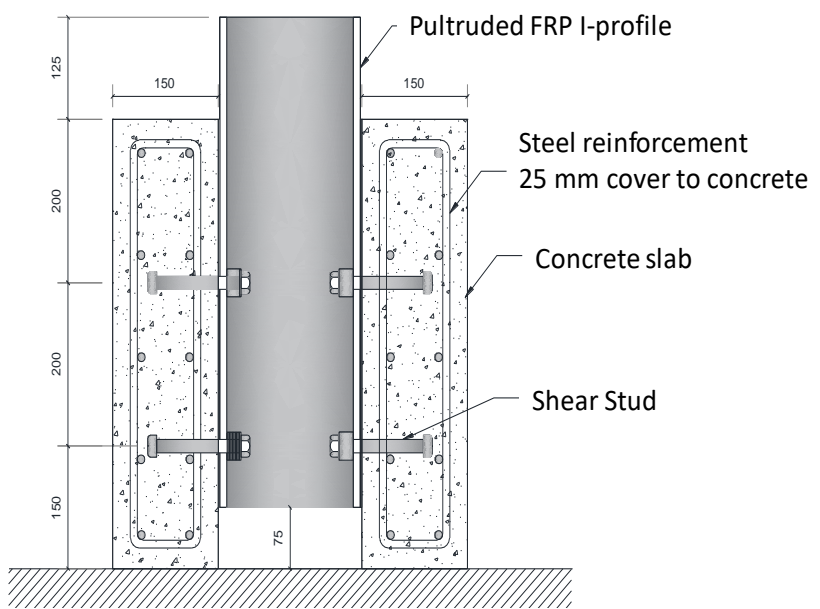

(c) Double row studs (PO-DR-S3)

Figure 3. Specimen Configurations

\subsection{Concrete Strength Properties}

Normal weight concrete (NWC) design was specified accordingly using the BRE standard method for the design of mix proportions. All concrete mixes for specimens tested in Phase I were cured from the same batch while that of specimens from Phase II was derived from different batches. Mechanical properties of the concrete specimens are presented in Table 1 below.

Table 1. Concrete cylinder/cube properties

\begin{tabular}{lcccccc}
\hline Specimen & BO-SR-S1 & PO-SG-S2 & PO-DR-S3 & PO-12B-S4 & PO-12B-S5 & PO-16B-S6 \\
\hline $\mathrm{ID}$ & & & & & \\
\hline $\mathrm{f}_{c k} / \mathrm{f}_{c u}$ & $47.24 / 49.89$ & $47.24 / 49.89$ & $47.24 / 49.89$ & $28.20 / 46.00$ & $27.80 / 45.30$ & $25.80 / 40.00$ \\
$(\mathrm{MPa})$ & & & & & & \\
$\mathrm{E}_{c m}(\mathrm{GPa})$ & $30.49 / 31.34$ & $30.49 / 31.34$ & $30.49 / 31.34$ & $23.56 / 30.09$ & $23.40 / 29.86$ & $22.54 / 28.06$ \\
\hline
\end{tabular}




\subsection{Test Set-Up and Instrumentation}

The test setup comprises of load cell mechanism designed to apply substantial loading to a significant degree for stud deformation or visible failure propagation on the composite section. The loading action was manually controlled with the mechanical use of a hand pump, which provided pressure to the hydraulic system subjecting the test specimen to a gradual load increase until experimental satisfaction. Every loading action (effort) and reactions within the system was captured and converted into interpretive data via a data logger system connected to a computer. A metal plate was positioned at the top of the GFRP section to distribute the load applied concentrically to the specimen. Two displacement transducers were placed on opposite sides of the plate to measure the longitudinal slip during loading of the I-section against the reinforced concrete slabs (Figure 4).

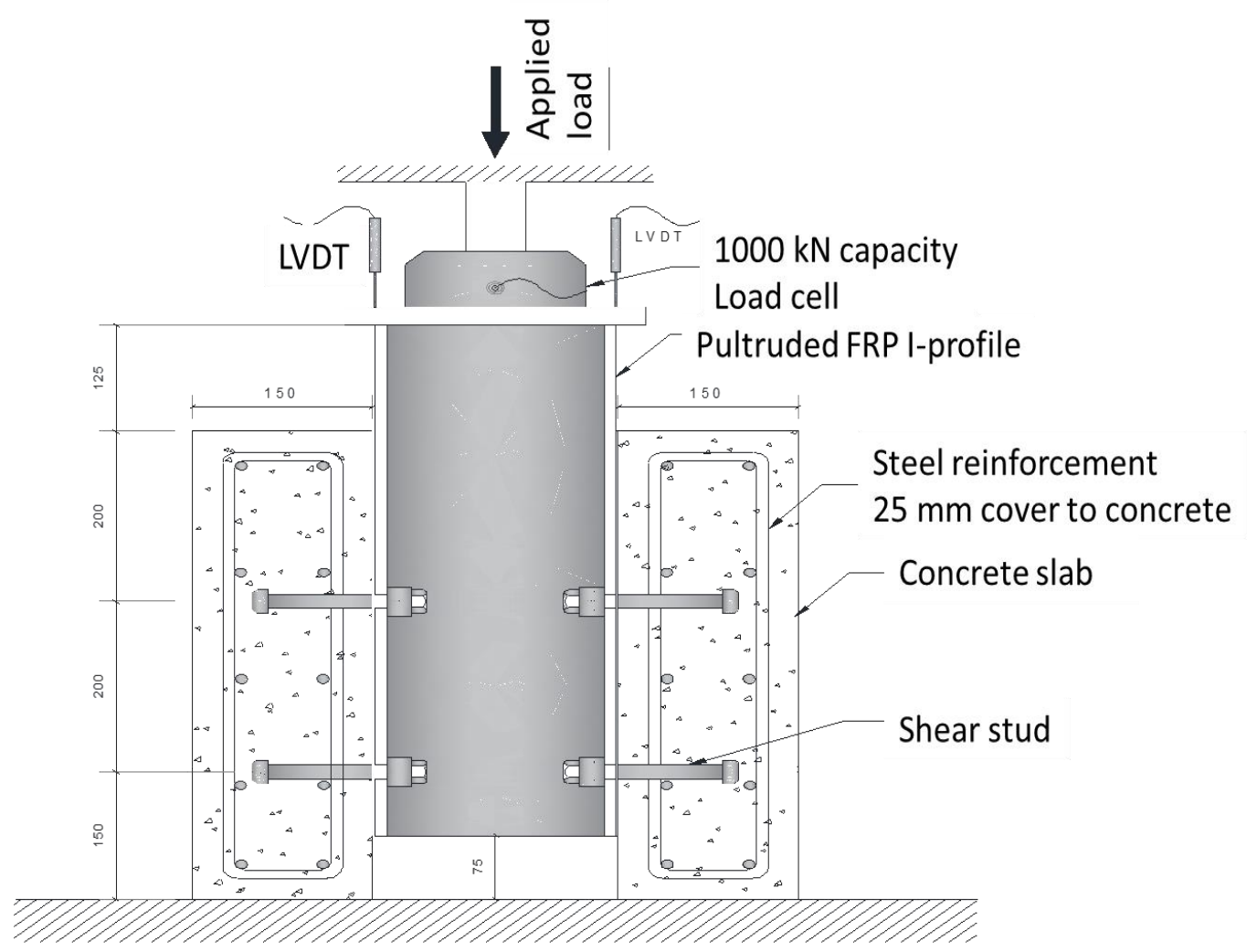

Figure 4. Experimental setup (schematic arrangement)

\section{RESULTS AND ANALYSIS}

The results obtained from all push-out specimens within the two phases of testing is reported and analysed to illustrate performance of composite connections. The analysis captured the mode of failures, shear capacity, stiffness and ductility of the connection. Summary of obtained experimental results for all specimen is presented in Table 2. 
Table 2. Summary of push-out test results

\begin{tabular}{|c|c|c|c|c|c|}
\hline $\begin{array}{c}\text { Specimen ID } \\
{[1]}\end{array}$ & $\begin{array}{l}\text { Peak } \\
\text { load, } \\
\mathrm{P}_{\mathrm{U}} \\
(\mathrm{kN}) \\
{[2]}\end{array}$ & $\begin{array}{c}\text { Slip at } \\
\text { peak } \\
\text { load, } \\
\mathrm{S}_{\mathrm{U}} \\
(\mathrm{mm}) \\
{[3]}\end{array}$ & $\begin{array}{l}\text { Experimental } \\
\text { strength } \\
\text { per stud } \\
\mathrm{P}_{\text {Exp, }}(\mathrm{kN}) \\
{[4]}\end{array}$ & $\begin{array}{c}\text { Stiffness } \\
\text { of shear } \\
\text { connection } \\
\text { K, } \\
(\mathrm{kN} / \mathrm{mm}) \\
{[5]}\end{array}$ & $\begin{array}{l}\text { Failure mode } \\
{[6]}\end{array}$ \\
\hline PO-SR-S1 & $\begin{array}{c}300 . \\
50\end{array}$ & 10.71 & 75.13 & 48.28 & $\begin{array}{l}\text { Bearing failure of } \\
\text { FRP flanges/bending } \\
\text { of shear stud/severe } \\
\text { delamination of FRP } \\
\text { flanges }\end{array}$ \\
\hline PO-SG-S2 & $\begin{array}{c}443 . \\
70\end{array}$ & 10.80 & 73.95 & 105.17 & $\begin{array}{l}\text { Bearing failure of } \\
\text { FRP flanges/bending } \\
\text { of shear stud/severe } \\
\text { delamination of FRP } \\
\text { flanges }\end{array}$ \\
\hline PO-DR-S3 & $\begin{array}{c}552 . \\
6\end{array}$ & 11.47 & 69.08 & 75.51 & $\begin{array}{l}\text { Bending of } \\
\text { flanges/tension/beari } \\
\text { ng failure (FRP) }\end{array}$ \\
\hline PO-12B-S4 & 333 & 8.0 & 41.63 & 62.50 & $\begin{array}{l}\text { Bearing failure of } \\
\text { FRP flanges/bending } \\
\text { of shear stud/severe } \\
\text { delamination of FRP } \\
\text { flanges }\end{array}$ \\
\hline PO-12B-S5 & 385 & 8.9 & 48.13 & 96.36 & $\begin{array}{l}\text { Bearing failure of } \\
\text { FRP flanges/bending } \\
\text { of shear stud/severe } \\
\text { delamination of FRP } \\
\text { flanges }\end{array}$ \\
\hline PO-16B-S6 & 431 & 10.9 & 53.84 & 110.00 & $\begin{array}{l}\text { Bearing failure of } \\
\text { FRP flanges/bending } \\
\text { of shear stud/severe } \\
\text { delamination of FRP } \\
\text { flanges }\end{array}$ \\
\hline
\end{tabular}

\subsection{Failure Mechanisms of the Composites}

Typical failure modes in steel-concrete composites are concrete sprawling or pull-out and stud fracture. Nguyen (2014) reported the failure mode observed from research investigations on FRP-concrete as dominantly bearing failure around the holes on the flanges of both HFRP (hybrid fibre reinforced polymer) and GFRP respectively. The general failure mode observed in the present testing corroborates with reports from Nguyen (2014) on the predominant bearing failures on the FRP flange (see Figure 5). Another important failure observation was the single curvature bending of the studs as described and reported by Nellinger (2017) for shear studs in solid slabs. However, the 
single curvature bending was more evident in stud size diameters less than $19 \mathrm{~mm}$ as no deformation was observed in $19 \mathrm{~mm}$ studs of any stud configuration tested in Phase I.

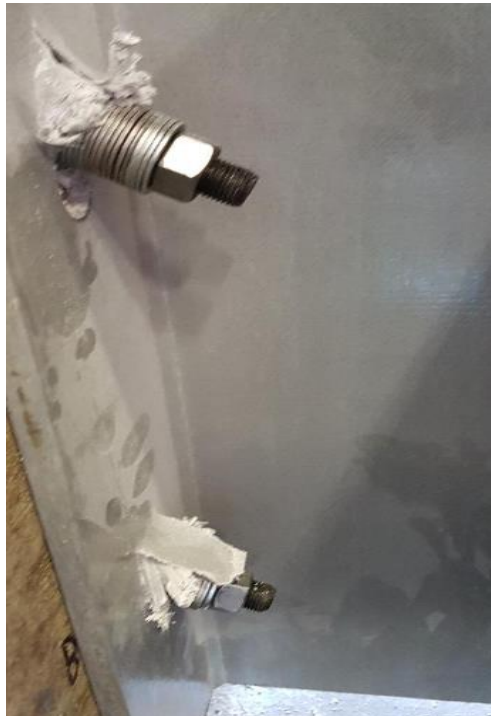

Figure 5. Specimen (a)

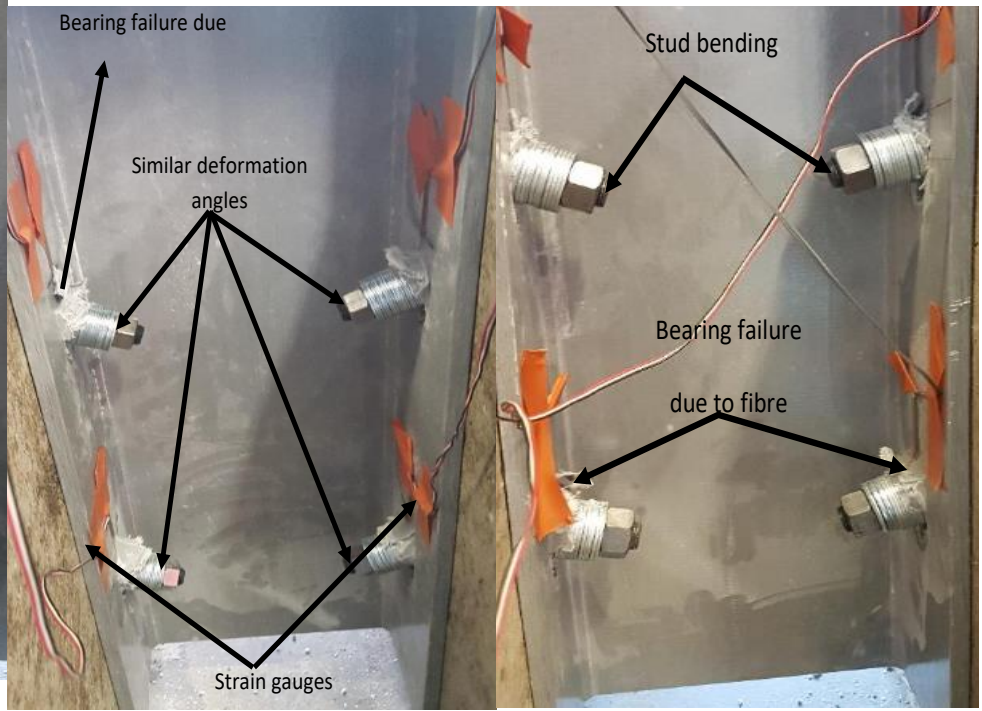

(c) PO-16B-S6

An additional type of failure called the "tensile tear out failure" on the FRP flange was observed with specimen PO-SR-S1 utilizing the $19 \mathrm{~mm}$ bolt. As mentioned earlier, the $19 \mathrm{~mm}$ stud hardly deformed and with the double-row configuration (PO-DR_S3), it provided more resistance to the shear load allowing for the increased vulnerability of the FRP flanges, which led to the tensile tear out failure (See Figure 6).
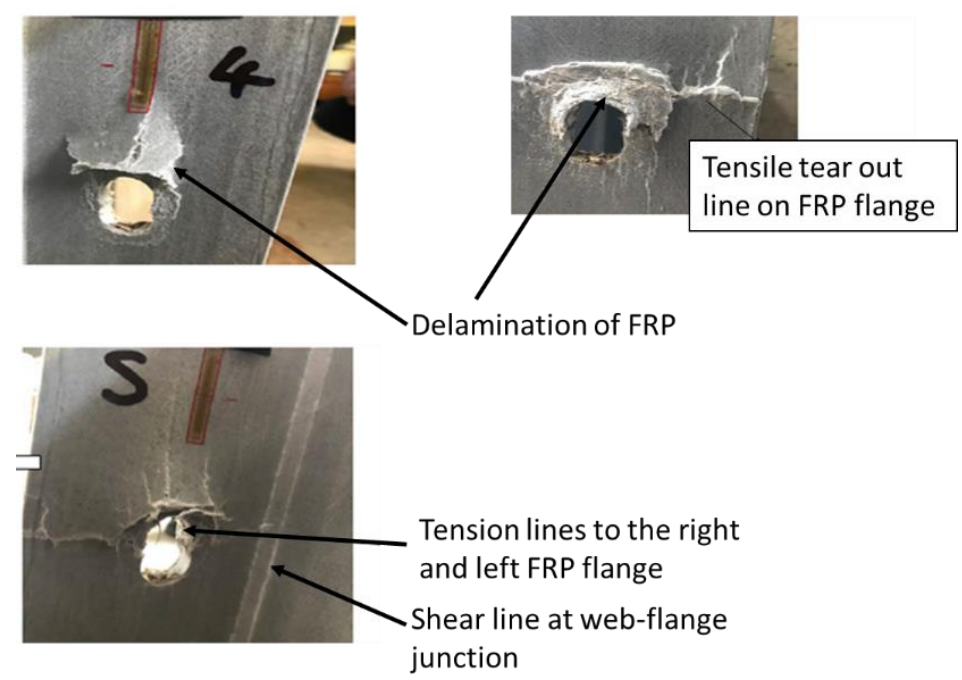

Figure 6. Failure on FRP flange 


\subsection{Load - Slip Relationship}

The Longitudinal slip was estimated from the average recorded slip of the transducers, LVDT1-LVDT4. The load versus slip curve for all six push-out specimens are presented in the graphs below (see Figure 7).

\subsubsection{Phase I Plots}

The load-slip curve for PO-SR-S1 (a single row or four bolt configuration) exhibited a fairly linear behaviour until a peak load of $300.5 \mathrm{kN}$ at mean longitudinal slip of $10.71 \mathrm{~mm}$. The curve extends a zigzag behaviour (bearing of FRP) from an increased load of $128 \mathrm{kN}$ till the failure load and post failure as can be seen in Figure 7. A postexperimental assessment of the concrete slabs showed no visible cracks on either of the slabs that might have been suggestive of the zigzag behaviour. However, it was common with all specimens and more suggestive of inner fibre delamination response to loading. After the ultimate resistance is reached, the curve exhibits a significant nonlinear and gradual drop in resistance up until failure. Pseudo-ductile behaviour is evident in the non-elastic zone, mainly as a result of the steel bolts. A similar behaviour was observed with the other two specimens (PO-SG-S2 and PO-DR-S3). PO-SG-S2 recorded an initial stiffness at loading of approximately $25 \mathrm{kN}$. Redistribution of loading with the shear studs seemed a likely occurrence in this setup as the shear response at yielding was slower before attending its peak at $443.7 \mathrm{kN}$ with a corresponding slip of $10.80 \mathrm{~mm}$. PO-DR-S3 (double row or 8 bolt configuration) evidently provided the highest shear resistance and became the adopted configuration for phase two testing. The ultimate load was obtained at $552.7 \mathrm{kN}$ with a corresponding slip of $11.47 \mathrm{~mm}$.
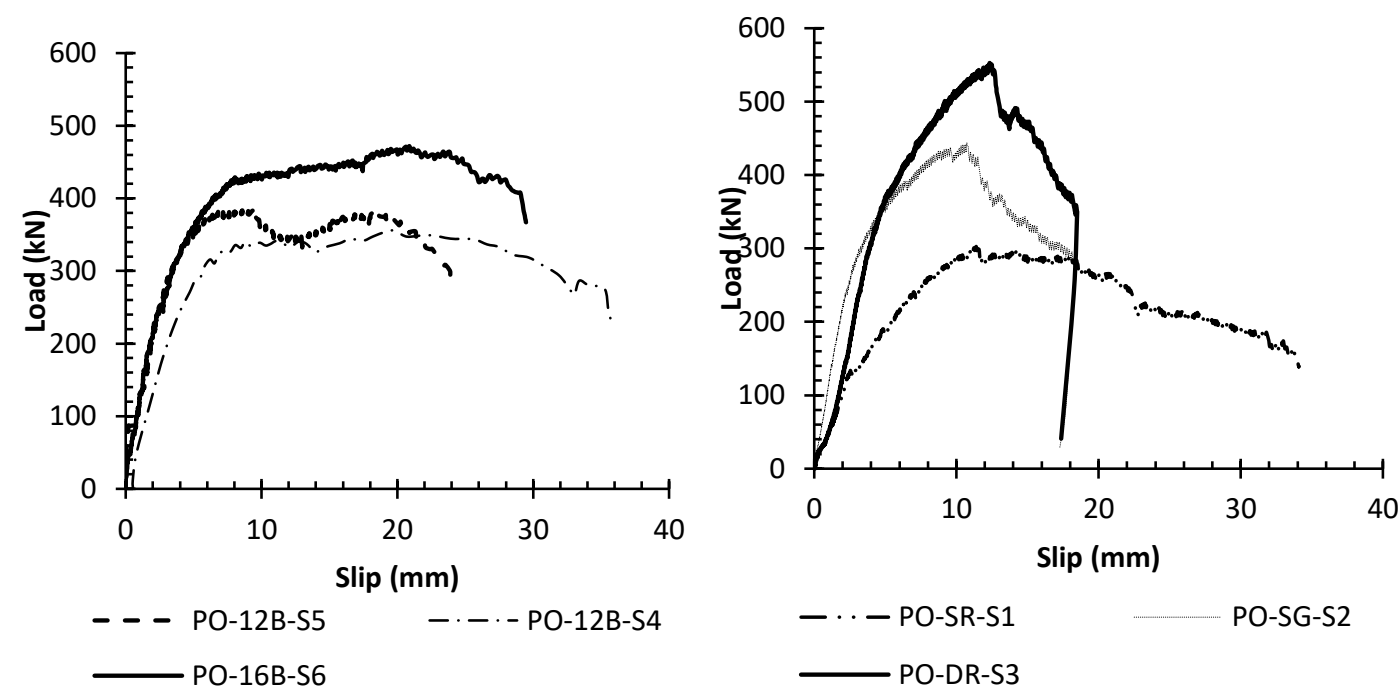

Figure 7. Load-slip plots

\subsubsection{Phase II Plots}

All three specimens behaved similarly and failed in a ductile manner (pseudo-ductility) indicating a combined simultaneous deformation of both stud and bearing failure on 
the FRP flange. The plot was characterised by a linear zone and a transitioning zone (at yielding) unto the nonlinear behavioural zone thereafter, up until failure. The peak loads and corresponding slips obtained are reported in Table 2. PO-12B S4 and PO12B-S5 were made of same stud size (12 $\mathrm{mm}$ stud size) and configuration however, PO-12B-S4 recorded a peak load which was $13.5 \%$ less than $385 \mathrm{kN}$ peak load attained by PO-12B-S5 with corresponding slips of $8 \mathrm{~mm}$ and $8.9 \mathrm{~mm}$ respectively. The reason for the difference in failure load may be due to a combine non-homogenous weakness in the FRP and a non-consistency in the concrete mix around the stud area for the various specimens

\subsubsection{PO-16B-S6 (16 mm stud) and PO-DR-S3 (19 mm stud) Comparison}

The generic behavior observed from the load -slip plots illustrates the dominant bearing propagation as a characteristic failure mode with the GFRP-concrete composites. The curve for the $19 \mathrm{~mm}$ stud (PO-DR-S3) illustrates a failure entirely dominated by bearing failure (typical of GFRP-concrete composites) even though there was a slight bending of the stud represented by the nonlinear zone (short curve just before the fall) of the curve, short-lived by the sudden fall from the peak suggesting the dominance of bearing failure/fiber delamination as an override to the stud deformation. PO-16B-S6 (16 mm studs) on the other hand, produces a large nonlinear zone illustrating ductility; only in this case, the ductility is made possible by a combined interaction of stud and flange panel failure (see Figure 8).

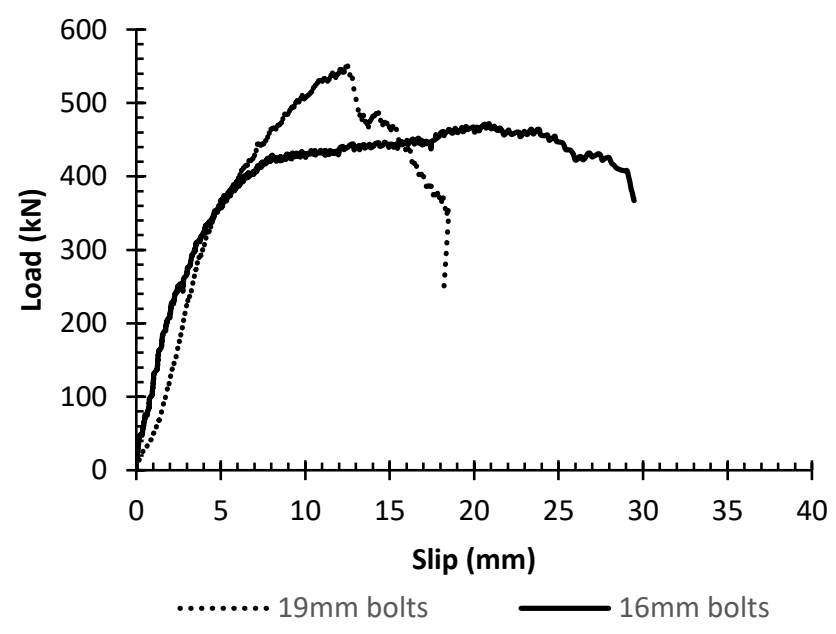

Figure 8. Load-slip Comparison (16 mm and $19 \mathrm{~mm}$ studs)

\section{DISCUSSION}

A general reliability on the contributing mechanical functions of all composite components is required to fully describe the shear capacity and failure mode of FRPconcrete composite. The inability of the shear studs to significantly deform under loading indicates that the FRP flange provided a weak resistance to the bearing pressure of the stud on the clearance holes hence, premature failure of the composite 
due to bearing. There is need to consider that the combine action of the flange properties and stud resistance will determine the necessary shear capacity of a given FRP-concrete composite connection.

\subsection{Shear Strength}

The ultimate shear strength of the $19 \mathrm{~mm}$ studs estimated from the load-slip plots are presented in Table 3. Subsequently, this load presents the peak performance within which the composites perform efficiently. The shear strength is further evaluated to determine the load resistance per bolt in each configuration as the study correlates the values of the performance and behaviour to achieve the objective of this research.

\subsubsection{Stud Configuration Comparison}

The load-slip plots for the experimental results from the push out test carried out on the various stud configurations has shown that increase in number of studs per connection will have a direct impact on the shear strength of the connection. The significant increase in shear capacity of the connection is reported as $48 \%$ and $84 \%$ respectively over specimen PO-SR-S1 for specimens PO-SG-S2 and PO-DR-S3. However, the percentage increase between 6-stud and 8-stud configurations is $25 \%$. Though the percentage difference in shear capacity between 6-studs and 8-studs configuration is lower when compared against 4-stud configuration, the shear strength per stud evaluation provides a different perspective to the stud influence on the shear capacity.

The average shear value per stud for PO-SR-S1 is approximately $2 \%$ higher than POSG-S2. This result implies that the use of a staggered bolt configuration may not be conservative in design for shear loads less than $300 \mathrm{kN}$ (or $50 \mathrm{MPa}$ ). There is a $5 \%$ increase in average shear value per stud of 6-stud configuration over the 8-stud configuration irrespective of the difference in the shear capacities of the two connections. Therefore, an improvement in shear resistance (up to $84 \%$ over the $4-$ stud configuration) can be achieved using the 8-stud configuration. Specimen PO-SR$\mathrm{S} 1$ has an average stud strength of approximately $8 \%$ over specimen PO-DR-S3, while this may not be as conservative as PO-SG-S2, it may be technically prudent to ensure a higher distribution of load for safety concerns due to fatigue by considering the 4bolt configuration against a 6-bolt in design but also conservative to adopt the 8-bolt configuration when the design load is estimated to be far less than the estimated capacity of the shear bolts.

Table 3. Shear capacity comparison for $19 \mathrm{~mm}$ stud configurations

\begin{tabular}{lcccc}
\hline $\begin{array}{c}\text { Stud } \\
\text { Configuration }\end{array}$ & $\begin{array}{c}\text { Shear } \\
\text { Capacity } \\
(\mathbf{k N})\end{array}$ & $\begin{array}{c}\text { Percentage } \\
\text { increase in shear } \\
\text { capacity } \\
(\boldsymbol{\%})\end{array}$ & $\begin{array}{c}\text { Average } \\
\text { shear } \\
\text { strength per } \\
\text { stud }(\mathbf{k N})\end{array}$ & $\begin{array}{c}\text { Percentage } \\
\text { decrease in } \\
\text { load } \\
\text { distribution } \\
(\boldsymbol{\%})\end{array}$ \\
\hline 4-Stud & 300.5 & - & 75.125 & - \\
\hline 6-Stud & 443.7 & 48 & 73.95 & 2 \\
\hline 8-Stud & 552.7 & 84 & 69.08 & 8 \\
\hline
\end{tabular}




\subsubsection{Stud Size Comparison}

There is a successive increase in shear capacity as the stud sizes increase. Apart from a $15.6 \%$ shear capacity disparity between the two specimens of $12 \mathrm{~mm}$ stud sizes (PO12B-S4 and PO-12B-S5), $16 \mathrm{~mm}$ and $19 \mathrm{~mm}$ stud size specimens have exhibited significant increase in shear capacities suggesting that the shear capacity of GFRPconcrete composites are influenced by stud sizes analogical to steel-concrete composites. There is a $29.4 \%$ and $65.7 \%$ successive increase for stud sizes $16 \mathrm{~mm}$ and $19 \mathrm{~mm}$ respectively.

Table 4. Comparative results of shear strength

\begin{tabular}{cccccc}
\hline $\begin{array}{c}\text { Stud Size } \\
(\mathrm{mm})\end{array}$ & $\begin{array}{c}\text { Experimental } \\
\text { Shear } \\
\text { Capacity } \\
(\mathrm{kN})\end{array}$ & $\begin{array}{c}\text { Experimental } \\
\text { Strength per } \\
\text { stud, }\end{array}$ & $\begin{array}{c}\text { Experimental results of shear } \\
(\mathrm{kN})\end{array}$ & $\begin{array}{c}\text { Exp } \\
\text { strength per stud for steel-concrete } \\
\text { push-outs }\end{array}$ \\
\cline { 5 - 7 } & & & Smith (2010) & $\begin{array}{c}\text { Prakash } \\
\text { et al. } \\
(2012)\end{array}$ & $\begin{array}{c}\text { Nellinger } \\
\text { et al. } \\
(2012)\end{array}$ \\
\hline 12 & 385.00 & 48.13 & - & - & - \\
\hline 16 & 431.00 & 53.84 & - & - & - \\
\hline 19 & 552.70 & 69.10 & 116.42 & - & 54.63 \\
\hline 20 & - & - & - & 132.00 & - \\
\hline
\end{tabular}

Some results for steel-concrete push-outs are reported above (Table 4) and compared against the current study. GFRP-concrete composites exhibit comparative shear strengths with steel-concrete counterparts. However, the failure modes are fundamentally different, evident from the differences in the shear capacity. For a 19 mm stud size, GFRP-concrete composites compare quite fairly with results reported by Nellinger (2012) on novel $19 \mathrm{~mm}$ demountable studs with shear strength per stud of about $54.63 \mathrm{kN}$. Smith et al (2010) reported strengths up to $116.42 \mathrm{kN}$ for a stud (high strength steel) diameter of $19 \mathrm{~mm}$ where the failure mode was either stud fracture and/or concrete sprawling.

\subsection{Shear Stiffness and Ductility}

The stiffness of the shear connection was estimated up to $110 \mathrm{kN} / \mathrm{mm}$ for specimen 6 with the $16 \mathrm{~mm}$ stud size (PO-16B-S6). The shear stiffness is approximately $50 \%$ comparable to steel-concrete shear stiffness of $223.81 \mathrm{kN} / \mathrm{mm}$ reported by Prakash et al. (2012) for $20 \mathrm{~mm}$ stud diameter. However, shear stiffness of connection for steelconcrete varies due to factors such as clearance holes, stud strength and concrete strength respectively. A 54\% difference in shear stiffness was observed for specimens with $12 \mathrm{~mm}$ stud sizes (PO-12B-S4 and PO-12B-S5) as specimen 5 was $35 \%$ higher than specimen 4 . This may be due to an initial slip during loading on the specimen owing to the bearing of the stud against the clearance hole on the FRP flange. The early slip might be suggestive of the significant difference in stiffness also attributed to a difference in torque applied to the stud. Specimen 2 amongst the three configurations exhibited a significant shear stiffness due to observed load 
redistribution among the studs during experimental testing. With the same stud size of $19 \mathrm{~mm}$, the staggered stud configuration had higher stiffness ranging between $28-$ $54 \%$ against the single and double row stud configurations. However, if concrete compressive strength is high and consistent, the stud stiffness for 12 and $16 \mathrm{~mm}$ sizes may be insignificantly similar. Also at peak loads, average slips up to $8 \mathrm{~mm}$ can be achieved with $12 \mathrm{~mm}$ stud sizes and higher slips with higher stud sizes consecutively. This observation satisfies the ductility requirements recommended on Eurocode 4. However, design may be based on a critical load which may be taken as $70 \%$ of the peak load with a corresponding slip of approximately $40 \%$ of the peak slip (slip at peak load). This consideration may contravene the $6 \mathrm{~mm}$ ductility requirement stated in Eurocode 4 for steel-concrete composites but becomes more reliable in providing a safe design against the pseudo-ductile behaviour of the connection.

\section{CONCLUDING REMARKS}

The test investigation for the GFRP-concrete carried out within two phases of experimental testing significantly highlights many benefits for the practical use of GFRP-concrete composites in construction. Some of the findings have conclusively described the behaviour of this composite and becomes highly informative for further research and design considerations. From the experimental investigation and analysis of the results the following conclusions can be drawn:

1. The shear capacity of GFRP-concrete composite is considerably sufficient to support structural static loads when compared with steel-concrete counterparts. The strength comparison is about $40 \%$ against high strength steel (HSS) studs and $100 \%$ for mild steel studs in steel-concrete connections. However, the shear capacity indicates a combined performance/interaction of the shear studs and FRP flange.

2. Larger stud sizes of $19 \mathrm{~mm}$ and above will result in extreme fibre failures across the clearance holes and therefore, it may be safe to adopt the $16 \mathrm{~mm}$ stud size as a higher stud boundary for GFRP-concrete composites.

3. Flange bearing failures dominantly characterize shear deformation for GFRPconcrete composites. This type of failure is capable of compromising the ductility of the connection. Critical load becomes imperatively relevant for a safe design assuming this load is defined as the load capable of initiating failure propagation on the GFRP flange during.

\section{ACKNOWLEDGEMENT}

The authors are particularly thankful to the technicians at the School of Energy, Construction and Environment, Coventry University for their assistance in the fabrication of the test specimens.

\section{Compliance with Ethical Standards}

The authors gratefully acknowledge the support of Engineered Composites, UK, suppliers of the FRP wide flange profiles. 


\section{Conflict of Interest:}

The authors declare that they have no conflict of interest.

\section{REFERENCES}

1. BS EN 1990:2002. Eurocode - Basis of structural design. (2002). London: British Standards Institution.

2. BS EN 1994-1-1: (2004) Eurocode 4: Design of Composite Steel and Concrete Structures. London: British Standards Institution.

3. Correia J., Branco J., Ferreira J., (2005), "Structural behavior of GFRP-concrete hybrid beams", Composites in Construction, $3^{\text {rd }}$ International Conference, France

4. Dai, X., Lam, D. and Saveri, E., (2015) "Effect of concrete strength and stud collar size to a shear capacity of demountable shear connectors". Journal of Structural Engineering 141 (11), 04015025.

5. Neagoe, C. and Gil, L., (2015), "Analytical procedure for the design of PFRP-RC hybrid beams including shear interaction effects". Composite Structures, 132, pp 122-135.

6. Nellinger, S. Odenbreit, C., Obiala R. (2017), "Influence of transverse loading onto push out test with deep steel decking". Journal of Constructional Steel Research. Volume 128, pp 335-353.

7. Nguyen, H., Mutsuyoshi, H., and Zatar, W. (2014), "Push-out tests for shear connections between UHPFRC slabs and FRP girder". Composite Structures [online] 118 (1), pp 528-547.

8. Nguyen, H. and Kim, S., (2009), "Finite element modelling of push-out tests for large stud shear connectors". Journal of Constructional Steel Research, 65(10-11), pp 1909-1920.

9. Prakash A., Anandavalli N., Madheswaran C.and Lakshmanan, N., (2012), "Modified push-out tests for determining shear strength and stiffness of HSS stud connector: Experimental study". International Journal of Composite Materials, 2(3), pp 22-31.

10. Smith A., Couchman G. (2010), "Strength and ductility of headed stud shear connectors in profiled steel sheeting", Journal of Constructional Steel Research. Volume 66, 6(748-754). 